\title{
Cardiopulmonary transplantation in children: a reason for optimism?
}

Heart transplants are now an established mode of treatment for heart failure in adults. Are they justified in children? We believe they are.

The aim is to provide a normal quality of life. However, for some, particularly those with an acute cardiomyopathy, it can be a question of life or death. Long term survival is limited by the development of coronary artery disease (probably as a result of chronic rejection) and posttransplant lymphoproliferative disease (PTLD). However, data from the International Society of Heart and Lung Transplantation (URL <www.ISHLT.org/regist>) shows a one year survival of $80 \%$, five year survival of $70 \%$, and a "half life" of 12.2 years.

So who should be considered? The ISHLT database shows roughly equal numbers of children with congenital heart disease and some form of cardiomyopathy, though this depends on the age group. In those under 1 year of age, over two thirds have congenital heart disease. In the older children (11-17 years of age) the ratio is reversed with most having a cardiomyopathy.

In patients with congenital heart disease, the indication is usually progressive decline in ventricular function although in some it may be intractable arrhythmias. Often it is a subjective decision by the child and their parents based on a poor quality of life. In contrast, patients with a cardiomyopathy may present with an acute episode. Although in most cases it is a dilated cardiomyopathy, patients with hypertrophic or indeed restrictive cardiomyopathies are seen. Bonnet and colleagues ${ }^{1}$ in a recent issue of Heart highlighted the rare but important cases which are caused by metabolic disorders - the screening of a child with cardiomyopathy is a very complex issue and is reviewed well by Schwartz and colleagues. ${ }^{2}$

Of the children presenting with a dilated cardiomyopathy, who should be referred for transplantation? The natural history is not well defined, making decisions difficult. This may reflect a disparate aetiology. It has been suggested that in those in whom a viral infection was the initial insult, recovery would be anticipated - the use of the polymerase chain reaction to detect enterovirus in the myocardium might be helpful. ${ }^{3}$ Conversely, the presence of fibroelastosis on the biopsy (especially in young children) suggests a poor outcome. ${ }^{4}$ Burch and colleagues ${ }^{5}$ have suggested that older age at presentation and lack of improvement of systolic function are associated with adverse outcome. In practical terms, we are guided by clinical progress.

\section{Poor ventricular function}

The child who presents acutely with poor ventricular function poses a particularly difficult challenge. Is it acute myocarditis, which might be expected to recover with treatment, or idiopathic cardiomyopathy? The Toronto group used endomyocardial biopsy to identify 36 children with acute lymphocytic myocarditis and concluded that they had a good outcome following treatment with immunosuppression. ${ }^{6}$ More recently, McCarthy and colleagues ${ }^{7}$ concluded that those with a fulminant form of myocarditis made a better recovery than those with a less severe illness. In contrast, the myocarditis treatment trial in adults did not support routine treatment of myocarditis with immunosuppression. ${ }^{8}$ The gold standard for the diagnosis of myocarditis is an endomyocardial biopsy and, although the Dallas criteria ${ }^{8}$ for histological classification are well established, their interpretation and application remain difficult. In view of the limited sensitivity and specificity of endomyocardial biopsy we have not found it helpful in the management of these children with an acute illness. In the future it may be possible to identify susceptible children and develop more precise treatment using gene targeting. ${ }^{9}$

Contraindications to heart transplant are few. We have undertaken combined heart and liver or heart and kidney transplants. While there are no anatomical arrangements which preclude a heart transplant, ${ }^{10}$ adverse physiology in the form of high pulmonary vascular resistance $(>6$ Wood units) is a definite contraindication. However, with the uncertainties involved in assessment of pulmonary vascular resistance, and the fact that the results of heart lung transplantation in children are suboptimal (see later), it is hard to be absolute. With a borderline pulmonary vascular resistance we would aim for an oversized heart or one from a domino procedure (patient undergoing heart lung transplant for cystic fibrosis).

At present, we match donor and recipient only for blood group and size-there is no time for HLA matching. In many children, particularly those with a cardiomyopathy, the heart is very enlarged and so there is the opportunity to use an oversized heart from a bigger donor. We have used hearts from donors with a body weight ratio of up to $3: 1$. We match the heart shadow on the recipient's chest $x$ ray with a silhouette from the donor chest $x$ ray.

At present some children still die waiting for a heart. Recently two strategies have emerged- "bridging to transplant" and, for infants, an ABO "mismatched" transplant. With an apparent shortage of donors, is "bridging to transplant" ethically justified? Figures from the UK transplant database show that the number of children (under the age of 16 years) undergoing heart transplantation in the UK is small-a range of 22-28 per year over the last six years. We know that in the paediatric age group, in contrast to the adult population, there are more donor hearts offered than there are recipients. However, in 1999, 15 children died on the UK heart transplant waiting list. On the other hand, in $1996-98$ only $25 \%$ of donor hearts offered in the $0-12$ age group were used while only $50 \%$ were used in the $12-16$ age group. Thus, there are donor hearts available, which are not being used. In conjunction with colleagues at Great Ormond Street Hospital we have begun a programme of mechanical assist using an external biventricular assist device (the Department of Health has just granted supraregional funding). This has the advantage over ECMO (extracorporeal membrane oxygenation) of providing pulsatile flow and using the patient's own lungs, thus reducing the complexity of, and complications from the circuit. To 
date, we have successfully transplanted four patients after "bridging" using the biventricular assist device.

\section{Transplantation in the neonate}

Heart transplantation in the neonate and young infant, where size matching is more critical, is still limited by the number of donors. The question of diagnosis of brain death in the neonates is a controversial one and the Hoffenberg report ${ }^{11}$ in 1987 concluded that the criteria used to diagnose brain stem death in adults should not be applied to neonates in the first seven days of life. ABO matching has to date been sacrosanct. However, it has been suggested recently that because of their immature immune system, newborns can develop tolerance. There have been sporadic reports of inadvertent $\mathrm{ABO}$ mismatch transplants performed in the adult population with a universally fatal outcome. However, West and colleagues ${ }^{12}$ from the Hospital for Sick Children in Toronto have just published their experience of $\mathrm{ABO}$ incompatible heart transplantation in 10 infants with a survival of $80 \%$ - the two early deaths were from causes unrelated to the $\mathrm{ABO}$ incompatibility. If this is borne out in larger studies (we have recently had success in two $\mathrm{ABO}$ mismatched infant transplants), then it becomes a realistic possibility to offer heart transplantation to more infants with complex congenital heart disease.

Finally, what of lung transplantation? The ISHLT Paediatric report $2000^{13}$ acknowledges that "evidence continues of striking improvement in patient survival post heart transplantation. Unfortunately this same era effect was not evident for paediatric lung or heart-lung recipients". The current "half life" for paediatric lung recipients is 3.7 years (compared to 12.2 years in heart recipients) with infection making a bigger contribution to mortality, especially in the first year. For this reason, few are performed (there were only 57 reported to the ISHLT database in 1999) and the majority of these were for primary lung conditions. Although a few centres have performed lung transplants in early childhood, ${ }^{14}$ we believe that lung recipients need to be old enough to perform pulmonary function tests satisfactorily to allow monitoring of potential rejection. Bronchiolitis obliterans continues to be the end point. Technically, patients with extreme forms of pulmonary atresia require heart lung transplantation, although on one occasion we have used heart and single lung with repair of a contralateral pulmonary artery. In those with Eisenmenger syndrome, the options include cardiac repair and a lung transplant (single or bilateral) or heart lung transplant. However, the slow decline in quality of life for patients with pulmonary vascular disease makes the timing of the decision to intervene very difficult. Thus, while donors are available (though size matching is more important) and previous thoracotomies are not a contraindication (intraoperative aprotinin has helped limit bleeding), we remain cautious in our approach. Starnes and colleagues ${ }^{15}$ have recently reported improved outcome following lung transplantation in children using living related donors. A cause for optimism?

J R LESLIE HAMILTON ASIF HASAN

Consultant Paediatric Cardiac Surgeons,

Freeman Hospital,

Nerwcastle upon Tyne, UK

leslie.hamilton@tfh.nuth.northy.nhs.uk

The authors are grateful to Professor J Dark, Director of Cardiopulmonary Transplantation, Freeman Hospital, Newcastle, for his helpful comments during preparation of this article.

1 Bonnet D, Rustin P, le Bidois J, et al. Heart transplantation in children with mitochondrial cardiomyopathy. Heart 2001;86:570-1.

2 Schwartz ML, Cox GF, Lin AE, et al. Clinical approach to genetic cardiomyopathy in children. Circulation 1996;94:2021-38.

3 Figulla HR, Stille-Siegener M, Mall G, et al. Myocardial enterovirus infection with left ventricular dysfunction: a benign disease compared with idiopathic dilated cardiomyopathy. $\mathcal{F}$ Am Coll Cardiol 1995:25:1170-5.

4 Matitiau A, Perez-Atayde A, Saunders SP, et al. Infantile dilated cardiomyopathy: relation of outcome to left ventricular mechanics, haemodynamics and histology at the time of presentation. Circulation 1994:90: 1310-18.

5 Burch M, Siddiqui SA, Celermajer D, et al. Dilated cardiomyopathy in children: determinants of outcome. Br Heart $\mathcal{f} 1994 ; 72: 246-50$.

6 Lee KJ, McCrindle BW, Bohn DJ, et al. Clinical outcomes of acute myocarditis in childhood. Heart 1999;82:226-33.

7 McCarthy RE, Boehmer JP, Hruban RH, et al. Long term outcome of McCarthy RE, Boehmer JP, Hruban RH, et al. Long term outcome of
fulminate myocarditis as compared with acute (non fulminant) myocardifulminate myocarditis as compared
tis. $N$ Engl $\mathcal{F}$ Med 2000;342:690-5.

tis. $N$ Engl f Med 2000;342:690-5.
8 Mason JW, O'Connell, Herskowitz A, et al. A clinical trial of immunosuppressive therapy for myocarditis. N Engl f Med 1995;333:269-75.

9 Opavsky, MA, Penninger J, Aitken K, et al. Susceptibility to myocarditis is dependent on the response of $\alpha \beta$ T lymphocytes to coxsackieviral infection. Circ Res 1999;85:551-5.

10 Hasan A, Hamilton JRL, Hunter S, et al. Orthotopic heart transplantation for congenital heart disease. Technical considerations. Eur $\mathcal{F}$ Cardiothorac Surg 1993; 7:65-70.

11 Hoffenberg R. Report of a working party on organ transplantation in neonates. Conference of Medical Royal Colleges, UK, 1987.

12 West LJ, Pollock-Barziv SM, Dipchand AI, et al. ABO incompatible heart transplantation in infants. N Engl F Med 2001;344:793-800.

13 Boucek M, Faro A, Novick RJ, et al. The Registry of the International Society for Heart and Lung Transplantation: Fourth official rediatric reportety for Heart and Lung Transplantation: Four

14 Spray TL, Bridges ND. Outcome of infants listed for lung or heart/lung transplantation. F Heart Lung Transplant 1991;18:1232-7.

15 Starnes VA, Woo MS, MacLaughlin EF, et al. Comparison of outcomes between living donor and cadaveric lung transplantation in children. Ann Thorac Surg 1999;68:2279-84. 